\title{
Synthesis and Characterization of $\mathrm{Y}_{2} \mathrm{O}_{3}$ Powders by a Modified Solvothermal Process
}

\author{
Kwang-Jin Jeong and Dong-Sik Bae ${ }^{\dagger}$ \\ Department of Convergence Materials Science and Engineering, \\ Changwon National University, Gyeongnam, 641-773, Korea
}

(Received November 22, 2011 : Received in revised form December 24, 2011 : Accepted January 17, 2012)

\begin{abstract}
Y}_{2} \mathrm{O}_{3}$ nanomaterials have been widely used in transparent ceramics and luminescent devices. Recently, many studies have focused on controlling the size and morphology of $\mathrm{Y}_{2} \mathrm{O}_{3}$ in order to obtain better material performance. $\mathrm{Y}_{2} \mathrm{O}_{3}$ powders were prepared under a modified solvothermal condition involving precipitation from metal nitrates with aqueous ammonium hydroxide. The powders were obtained at temperatures at $250^{\circ} \mathrm{C}$ after a $6 \mathrm{~h}$ process. The properties of the $\mathrm{Y}_{2} \mathrm{O}_{3}$ powders were studied as a function of the solvent ratio. The synthesis of $\mathrm{Y}_{2} \mathrm{O}_{3}$ crystalline particles is possible under a modified solvothermal condition in a water/ethylene glycol solution. Solvothermal processing condition parameters including the $\mathrm{pH}$, reaction temperature and solvent ratio, have significant effects on the formation, phase component, morphology and particle size of yttria powders. Ethylene glycol is a versatile, widely used, inexpensive, and safe capping organic molecule for uniform nanoparticles besides as a solvent. The characterization of the synthesized $\mathrm{Y}_{2} \mathrm{O}_{3}$ powders were studied by XRD, SEM (FE-SEM) and TG/ DSC. An X-ray diffraction analysis of the synthesized powders indicated the formation of the $\mathrm{Y}_{2} \mathrm{O}_{3}$ cubic structure upon calcination. The average crystalline sizes and distribution of the synthesized $\mathrm{Y}_{2} \mathrm{O}_{3}$ powders was less than 2 um and broad, respectively. The synthesized particles were spherical and hexagonal in shape. The morphology of the synthesized powders changed with the water and ethylene glycol ratio. The average size and shape of the synthesized particles could be controlled by adjusting the solvent ratio.
\end{abstract}

Key words $\underline{\mathrm{Y}}_{2} \underline{\mathrm{O}}_{3}$ powder, modified solvothermal process.

\section{Introduction}

Yttrium oxide $\left(\mathrm{Y}_{2} \mathrm{O}_{3}\right)$ is an important engineering materials in many fields due to its chemical and physical properties, such as high permittivity, ${ }^{1)}$ high melting point, a relatively large band gap energy etc. $\mathrm{Y}_{2} \mathrm{O}_{3}$ nanomaterials have been widely used in transparent ceramics and luminescent devices. Recently there are many studies focusing on controlling the size and morphology of $\mathrm{Y}_{2} \mathrm{O}_{3}$ in order to obtain better materials performance. For example, $\mathrm{Y}_{2} \mathrm{O}_{3}$ could be used as a waveguide material due to its high refractive index, or as a buffer layer for ferroelectrics and superconductors because of its low lattice-mismatch with silicon. ${ }^{2)}$ Yttria finds many high technology applications due to its excellent high affinity for oxygen and sulfur and well-defined crystal structures, whose properties can be tailored by incorporating different types of ions into the structure. ${ }^{3,4)}$ Yttria is used as a host matrix for phosphors used in televisions and also in synthesis of yttria-thoria type translucent ceramics for lasers. Yttria is also being tried as a mould coating for precision

Corresponding author

E-Mail : dsbae7@changwon.ac.kr (D. S. Bae)
Ti-6Al-4V castings. ${ }^{5)}$ In view this, yttria still attracts researchers for developing newer and better routes for its preparation in nano-crystalline range.

In recent years, nanocrystals have attracted researchers interest because of their unusual behavior. ${ }^{6,7)}$ Rare earth related nanocrystals, ${ }^{8,9)}$ especially the nanosized yttrium oxide $\left(\mathrm{Y}_{2} \mathrm{O}_{3}\right)$ with controllable size and morphology, which may have better sintering ability and unique luminescent property, have been widely studied because of their potential applications in transparent ceramics and luminescent devices, ${ }^{10,11)}$ such as FED and CRT, etc. For example, $\mathrm{Y}_{2} \mathrm{O}_{3}: \mathrm{Eu}^{3+}$ is the prominent red emitting phosphor with high luminescence quantum efficiency, and widely used in lamps and display, $\mathrm{Y}_{2} \mathrm{O}_{3}$ also can be used as advanced ceramics, ${ }^{12,13)}$ superconductor, ${ }^{14)}$ insulator $^{15)}$ and sensor. ${ }^{16)}$ $\mathrm{Y}_{2} \mathrm{O}_{3}$ nanostructures such as nanotubes, ${ }^{17)}$ nanowires, ${ }^{18)}$ nanorods ${ }^{19)}$ nanobelts, ${ }^{20,21)}$ nanodisks ${ }^{22)}$ and nanosheets ${ }^{23)}$ have been prepared. However, the synthesis and self-assembly of $\mathrm{Y}_{2} \mathrm{O}_{3}$ microstructures have been rarely reported.

Various Chemical routes such as spray drying, ${ }^{24)}$ coprecipitaion $^{25)}$ and sol-gel ${ }^{26)}$ are known to yield sinter-active materials. Yttria powders obtained after thermal decomposition of yttrium precursors at high temperatures (carbonates, oxalate, nitrate and hydroxide) require tempera- 
tures in excess of $1873 \mathrm{~K}$ for sintering. ${ }^{27)}$

Among the many different methods listed above, Hydrothermal processes have a potential for the direct preparation of crystalline ceramic powders and offer a low temperature alternative to conventional powder synthesis techniques in the production of oxide powders. ${ }^{28)}$ This technique can produce fine, high purity, stoichiometric particles of single and multicomponent metal oxides. ${ }^{29)}$ Furthermore, if the process conditions such as solution $\mathrm{pH}$, solute concentration, reaction temperature, reaction time, seed materials, and the type of solvent are carefully controlled, ceramic particles of the desired shape and size can be produced. $^{30)}$

The objective of this study is to prepare the yttria powders by a modified solvothermal process, and to investigate the effects of the processing conditions on the formation, morphology, size and phase of the powders.

\section{Experimental Procedure}

The preparation sequence of yttria powder is schematically illustrated in Fig. 1.

Yttrium Nitrate (99.99\%, DAE JUNG, Korea) was dissolved with $100 \mathrm{ml}$ deionized water to the concentration of $0.2 \mathrm{M}$. Yttria precursors were precipitated from $0.2 \mathrm{M}$ solution by slowly adding $\mathrm{NH}_{4} \mathrm{OH}$ with rapid stirring in which the $\mathrm{pH}$ of starting solutions varied between 7 and 11 . The precipitated yttria precursors were washed by respected cycles of centrifugation and re-dispersion in water. Washing was performed for a minimum of two times in water and

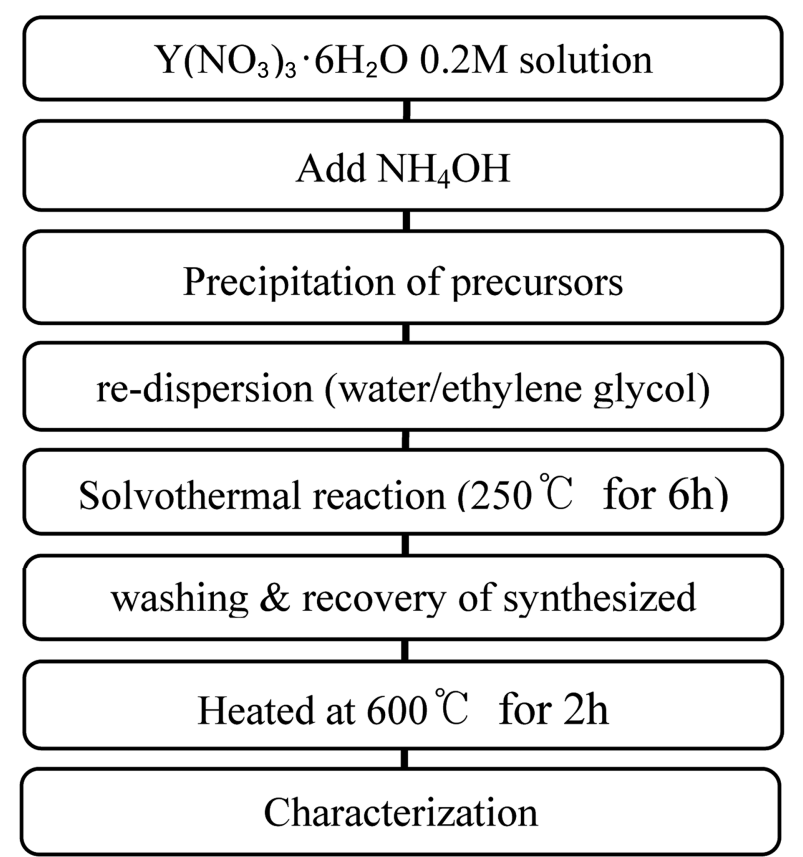

Fig. 1. Experimental flow chart of synthesized yttria powders by a modified solvothermal process. three times in ethanol. Excess solution was decanted after the final washing and the wet precursor was re-dispersed in adequately ratio of the water/ethylene glycol under vigorous stirring. After that the colloidal mixture was transferred into a $1000 \mathrm{ml}$ stainless steel autoclave and sealed.

The autoclave was then heated to the $250^{\circ} \mathrm{C}$ at a rate of $5^{\circ} \mathrm{C} / \mathrm{min}$ for $6 \mathrm{~h}$. The reaction products were washed at least five times by repeated cycles of centrifugation and re dispersion in ethanol and D.I. Water. The characterization of the recovered powders was observed using X-Ray Diffraction (XRD, MiniFlex II), Thermogravimetry and Differential Scanning Calorimetry (TG-DSC) and Field Emission Scanning Electron Microscope (FE-SEM, MIRA II LMH).

\section{Results and Discussion}

Solvothermal processing conditions such as $\mathrm{pH}$, reaction temperature and solvent ratio, have significant effects on the formation, phase component, morphology and particle size of yttria powders. Ethylene glycol is a versatile widely used, cheap, and safe capping organic molecules for uniform nanoparticles except as a solvent. ${ }^{31-33)}$ Fig. 2 shows the XRD patterns of the synthesized powders obtained reaction at $250^{\circ} \mathrm{C}$ for $6 \mathrm{~h}$. The detectable diffraction peaks in the pattern can be well indexed to the yttrium hydroxide (JCPDS card no. 09-0062) and yttrium oxide hydroxide nitrate (JCPDS card no. 79-1352). Fig. 3 shows the XRD pattern of the synthesized yttria powders after heat treatment at $600^{\circ} \mathrm{C}$ for $2 \mathrm{~h}$. The detectable four strong and broad peaks at $2 \theta \fallingdotseq 29.2,33.8,48.5$ and $57.6^{\circ}$ are present in the XRD pattern, which can be assigned to (222), (400), (440) and (622) reflections of cubic $\mathrm{Y}_{2} \mathrm{O}_{3}$

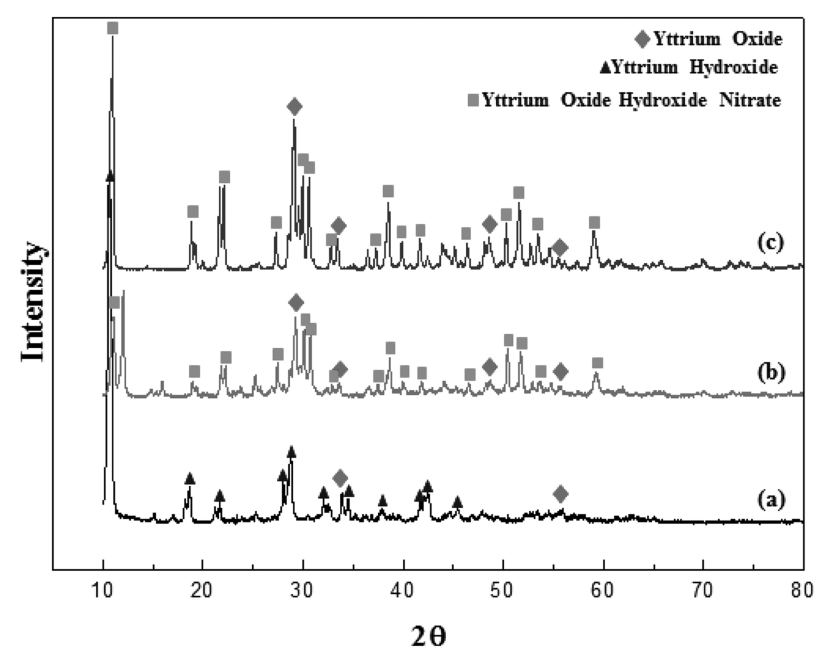

Fig. 2. X-ray diffraction pattern of yttria powders synthesized reaction at $250^{\circ} \mathrm{C}$ for $6 \mathrm{~h}$ as a function of solvent (water/ethylene glycol) ratio ; (a) 1:9, (b) 1:1 and (c) 9:1. 


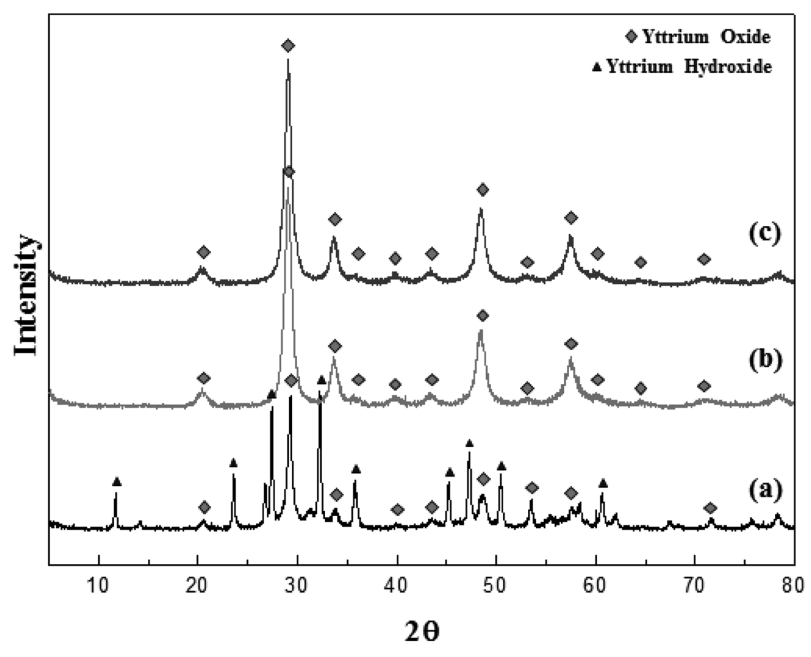

Fig. 3. X-ray diffraction pattern of yttria powders synthesized by a modified solvothermal processing with heat treatment at $600^{\circ} \mathrm{C}$ for $2 \mathrm{~h}$ as a function of solvent (water/ethylene glycol) ratio ; (a) 1:9, (b) $1: 1$ and (c) $9: 1$.

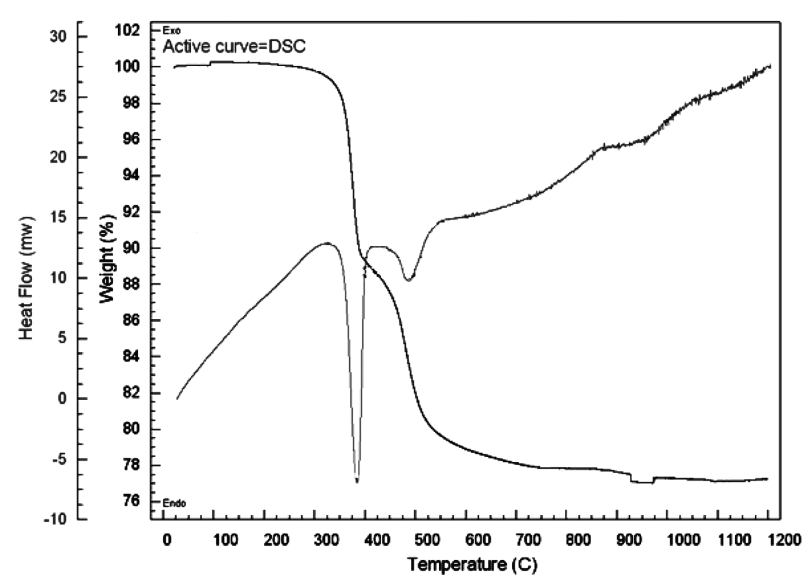

Fig. 4. TG-DSC curves of synthesized $\mathrm{Y}_{2} \mathrm{O}_{3}$ powders reaction at $250^{\circ} \mathrm{C}$ for $6 \mathrm{~h}$.

respectively (JCPDS card no. 89-5591). However, the phase of the synthesized powder was mixed $\mathrm{Y}(\mathrm{OH})_{3}$ and $\mathrm{Y}_{2} \mathrm{O}_{3}$ with water to ethylene glycol ratio is 1 to 9 .

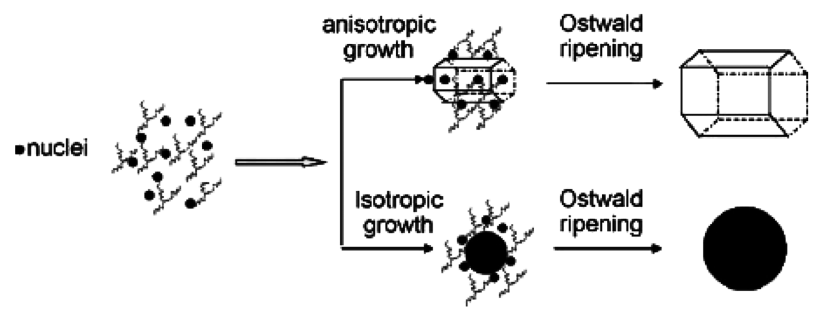

Fig. 5. The schematic illustration of the formation mechanism of $\mathrm{Y}_{2} \mathrm{O}_{3}$ in ethylene glycol at mild temperature and pressure condition.

Fig. 4 shows the TG-DSC curves of the synthesized $\mathrm{Y}_{2} \mathrm{O}_{3}$ powders reaction at $250^{\circ} \mathrm{C}$ for $6 \mathrm{~h}$. The TG-DSC curves showed two step weight loss of ca. $22 \%$ with two endothermic peaks at about $380^{\circ} \mathrm{C}$ and $485^{\circ} \mathrm{C}$ which may be due to combustion of residual organics.

The schematic illustration of the formation mechanism of $\mathrm{Y}_{2} \mathrm{O}_{3}$ in ethylene glycol at mild temperature and pressure condition. ${ }^{34)}$ In this case, when the concentration of ethylene glycol is low, only certain facets of the nuclei are attached with ethylene glycol ions and lead to an anisotropic growth of the $\mathrm{Y}_{2} \mathrm{O}_{3}$ and hexagonal are obtained. Increasing the concentration of ethylene glycol, all the facets of the nuclei are absorbed with ethylene glycol ions and the growth rates in all directions are similar, and thus microspheres are obtained.

The samples were observed under SEM, and the corresponding images are shown in Fig 5. The morphology of the obtained $\mathrm{Y}_{2} \mathrm{O}_{3}$ powders was characterized by scanning electron microscope (SEM) observations. As shown in Fig. 5, the average crystalline sizes and morphology of the synthesized $\mathrm{Y}_{2} \mathrm{O}_{3}$ particles changed with water to ethylene glycol ratio. The average size and shape of the synthesized powders was $0.5-1 \mathrm{um}$ and spherical reaction at $250^{\circ} \mathrm{C}$ for $6 \mathrm{~h}$ in water to ethylene glycol ratio 1 to 9 . The morphology of the synthesized powders are almost hexagonal with diameters about $0.5 \sim 1$ um and length about 2 um after the reaction at $250^{\circ} \mathrm{C}$ for $6 \mathrm{~h}$ in water to ethylene glycol ratio 9 to 1 .

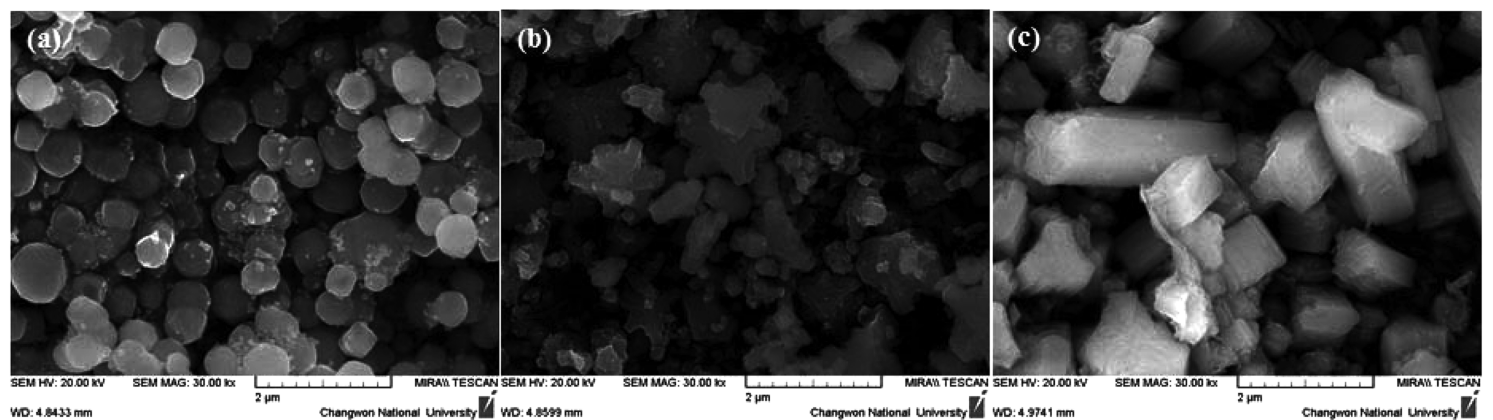

Fig. 6. SEM images of yttria powders synthesized reaction at $250^{\circ} \mathrm{C}$ for $6 \mathrm{~h}$ after heat treatment at $600^{\circ} \mathrm{C}$ for $2 \mathrm{~h}$ as a function of solvent (water/ethylene glycol) ratio ; (a) 1:9, (b) 1:1 and (c) 9:1. 


\section{Conclusion}

Yttria powders were synthesized by a modified solvothermal processing reaction at $250^{\circ} \mathrm{C}$ for $6 \mathrm{~h}$. The crystal structure and morphology were characterized by XRD, TG-DSC and FE-SEM. The detectable four strong and broad peaks at $2 \theta \fallingdotseq 29.2,33.8,48.5$ and $57.6^{\circ}$ are present in the XRD pattern, which can be assigned to (222), (400), (440) and (622) reflections of cubic $\mathrm{Y}_{2} \mathrm{O}_{3}$ respectively (JCPDS card no. 89-5591). However, the phase of the synthesized powder was mixed $\mathrm{Y}(\mathrm{OH})_{3}$ and $\mathrm{Y}_{2} \mathrm{O}_{3}$ with water to ethylene glycol ratio is 1 to 9 . The average crystalline sizes and morphology of the synthesized $\mathrm{Y}_{2} \mathrm{O}_{3}$ particles changed with water to ethylene glycol ratio. The average size and shape of the synthesized powders was $0.5-1$ um and spherical after the reaction at $250^{\circ} \mathrm{C}$ for $6 \mathrm{~h}$ in water to ethylene glycol ratio 1 to 9 . The average particle size and distribution of the synthesized yttria powders were in the range of $0.5 \sim 2$ um and broad, respectively. In this study, the distilled water and ethylene glycol play critical roles in the formation of the $\mathrm{Y}_{2} \mathrm{O}_{3}$ particles.

\section{Acknowledgment}

This work was supported by the National Research Foundation of Korea (NRF) grant funded by the Korea government (MEST) (No. 2011-0030802).

\section{References}

1. G. D. Wilk, R. M. Wallace and J. M. Anthony, J. Appl. Phys., 89, 5243 (2001).

2. P. de Rouffignac, J. S. Park and R. G. Gordon, Chem. Mater., 17, 4808 (2005).

3. N. McN. Alford, J. D. Birchall, W. J. Clegg, M. A. Harmer, K. Kendall and D. H. Jones, J. Mater. Sci., 23, 761 (1988).

4. B. T. Kilbourn, Encyclopedia of Materials Science and Engineering vol. 7, p. 5509-5510, ed. M. B. Bever, Pergamon Press Ltd., Oxford, UK (1986).

5. T. Okuda, S. Nomura, S. Sillkakura, K. Asabe, S. Tanouf and M. Fujiwara, in Proceedings of the International Conference on Solid State Powder Processing (Indianapolis, USA October 1989), ed. A. H. Clauer and J. J. de Barbadillo (The Minerals, Metals and Materials Society, TMS, USA, 1990) p. 195-202.

6. X. Wang, J. Zhuang, Q. Peng and Y. Li, Nature, 437 (7055), 121 (2005).

7. R. Si, Y. -W. Zhang, L. -P. You and C. -H. Yan, Angew. Chem. Int. Ed., 44(21), 3256 (2005).

8. G. Xu, Y. -W. Zhang, C. -S. Liao and C. -H. Yan, J. Am. Ceram. Soc., 87(12), 2275 (2004).

9. X. Wang, X. -M. Sun, D. Yu, B. -S. Zou and Y. Li, Adv. Mater., 15(17), 1442 (2003).
10. C. R. Ronda, T. Justel and H. Nikol, J. Alloy. Comp., 275-277, 669 (1998).

11. Takayasu Ikegami, Ji-Guang Li, Toshiyuki Mori and Yusuke Moriyoshi, J. Am. Ceram. Soc., 85, 1725 (2002).

12. B. N. Kim, K. Hiraga, K. Morita and Y. Sakka, Nature, 413, 288 (2001).

13. A. Rosenflanz, M. Frey, B. Endres, T. Anderson, E. Richards and C. Schardt, Nature, 430, 761 (2004).

14. T. S. Lin, L. G. Sobotka and W. Froncisz, Nature, 333, 21 (1988).

15. K. Nomura, H. Ohta, A. Takagi, T. Kamiya, M. Hirano and H. Hosono, Nature, 432, 488 (2004).

16. A. M. E. Suresh Raj, C. M. Magdalane and K. S. Nagaraja, Phys. Status Solidi, 191, 230 (2002).

17. X. Wang, X. M. Sun, D. Yu, B. S. Zou and Y. Li, Adv. Mater., 15, 1442 (2003).

18. X. Wu, Y. Tao, F. Gao, L. Dong and Z. Hu, J. Cryst. Growth, 277, 643 (2005).

19. Z. Xu, Z. Hong, Q. Zhao, L. Peng and P. Zhang, J. Rare Earths, 24, 111 (2006).

20. M. Han, N. E. Shi, W. L. Zhang, B. J. Li, J. H. Sun, K. J. Chen, J. M. Zhu, X. Wang and Z. Xu, Chem. Eur. J., 14, 1615 (2007).

21. X. Li, Q. Li, Z. Xia, L. Wang, W. Yan, J. Wang and R. I. Boughton, Cryst. Growth Des., 6, 2193 (2006).

22. R. Si, Y. W. Zhang, L. P. You and C. H. Yan, Angew. Chem. Int. Ed., 44, 3256 (2005).

23. A. Towata, M. Sivakumar, K. Yasui, T. Tuziuti, T. Kozuka and Y. Iida, J. Mater. Sci., 43, 1214 (2008).

24. M. D. Rasmunssen, M. Akinc, D. Milius and M. G. McTaggart, Ceram. Bull., 62(2), 314 (1985).

25. P. Maestro, D. Huguenin, A. Seigneurin, F. Deneuve, P. Le Lann and J. F. Berar, J. Elecrochem. Soc., 139, 1479 (1992).

26. T. Hours, P. Bergez, J. Charpin, A. Larbot, C. Guizard and L. Cot, Ceram. Bull., 71, 200 (1992).

27. L. R. Furlong and L. P. Domingues, Ceram. Bull., 45, 1501 (1966).

28. H. J. Kim, J. H. Son and D. S. Bae, Kor. J. Mater. Res., 21(8), 415 (2011).

29. D. S. Bae, K. S. Han, S. B. Cho and S. H. Choi, J. Kor. Associ. Cryst. Growth, 17(1), 167 (1997).

30. S. B. Cho, S. Venigalla, J. H. Adair, Science, Technology and Applications of Colloidal Suspensions, p. 139-150, ed. J. H. Adair, J. A. Casey, C. A. Randall and S. Venigalla, American Ceramic Society, USA (1995).

31. Y. Wang, X. Jiang and Y. Xia, J. Am. Chem. Soc., 125, 16176 (2003).

32. L. Jiang, G. Sun, Z. Zhou, S. Sun, Q. Wang, S. Yan, H. Li, J. Tian, J. Guo, B. Zhou and Q. Xin, J. Phys. Chem. B, 109, 8774 (2005).

33. C. Feldmann, Adv. Funct. Mater., 13, 101 (2003).

34. S. Zhong, S. Wang, Q. Liu, Y. Wang, S. Wang, J. Chen, R. Xu and L. Luo, Mater. Res. Bull., 44, 2201 (2009). 